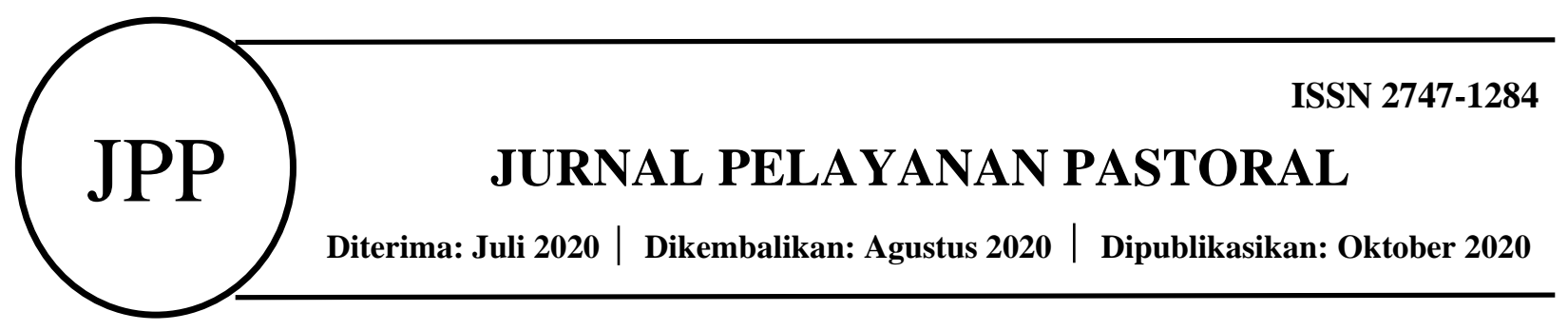

\title{
MANAJEMEN PESERTA DIDIK ANAK BERKEBUTUHAN KHUSUS MELALUI PENDEKATAN LINGKUNGAN INKLUSI RAMAH PEMBELAJARAN (LIRP) PADA SEKOLAH DASAR REGULER
}

\author{
Maria Yulianti Goo*1 \\ ${ }^{1}$ Sekolah Tinggi Pastoral -IPI Malang \\ Jurusan Pastoral Sosial, Prodi Pelayanan Pastoral \\ e-mail: ${ }^{1}$ yantigooalma@gmail.com
}

\begin{abstract}
Abstrak
Tujuan penyusunan artikel ini adalah mendeskripsikan manajemen peserta didik anak berkebutuhan khusus melalui pendekatan LIRP. Metode yang digunakan adalah deskriptif kualitatif. Teknik pengumpulan data dengan mengkaji literatur, observasi dan wawancara di lapangan dengan para pelaku pendidikan inklusi di sekolah inklusi. Hasil yang diperoleh bahwa manajemen peserta didik anak berkebutuhan khusus dengan pendekatan lingkungan inklusi ramah pembelajaran adalah sebuah proses dalam memberdayakan sumberdaya manusia yang ada di sekolah sebagai subyek pendidikan, dimana semua pelaku pendidikan ini saling memberdayakan diri melalui proses interaksi sosial, dengan tujuan mengasah kepekaan akfektif dan kecerdasan secara kognitif. Dengan demikian sekolah dasar reguler yang terinklusi adalah sarana untuk menciptakan lingkungan perkembangan seluruh aspek kehidupan peserta didik yang berkebutuhan khusus dan pelaku pendidikan lainnya dengan lebih optimal. Dari hasil penelitian ini, satu rekomendasi sebagai catatan bagi para pembuat kebijakan dan penyelenggara pendidikan inklusi supaya menyediakan sumberdaya yang memadai bagi layanan anak berkebutuhan khusus seprti tenaga tarapis, psikolog, dokter dan ditempatkan di sekolah-sekolah reguler yang terinklusi.
\end{abstract}

Kata kunci: Manajemen Peserta Didik, Anak Berkebutuhan Khusus, Lingkungan Inklusi, Ramah Pembelajaran

\begin{abstract}
The purpose of compiling this article is to describe the management of students with special needs by using a qualitative descriptive method through literature review, observation and interviews in the field with inclusion in school education. Through literature review to see theories and be used as a reference source. The observation intended by the author made direct observations in the field while the interview, the author conducted interviews to explore and obtain information from reliable informants related to the implementation of management of students with special needs with an inclusive and friendly learning approach in regular elementary schools. The results obtained that the management of students with special needs with a friendly learning inclusion environment approach is a process in empowering existing human resources in the school as the subject of education, where all these educational actors empower themselves through the process of social interaction, with the aim of honing effective sensitivity and cognitive intelligence. Thus a regular primary school that is included is a means to create an environment for the development of all aspects of the lives of students with special needs and other educational actors more optimally. From the results of this study, one recommendation is a note for policy makers and providers of inclusive education to provide adequate resources for services for children with special needs such as medical workers, psychologists, doctors and placed in inclusion in regular schools.
\end{abstract}

Keywords: Management of students, Disabilities, Inclusive environment, friendly learning 


\section{PENDAHULUAN}

Pendidikan merupakan hak semua orang dalam usaha mencerdaskan diri, mengembangkan minat, bakat juga potensi-potensi yang ada di dalam diri sesorang, termasuk anak-anak berkebutuhan khusus, namun masih sering dijumpai anak-anak berkebutuhan khusus belum diberi ruang atau lingkungan yang aman dan nyaman dalam proses pembelajaran yang sesuai dengan kondisi dan keadaaan anak berkebutuhan khusus. Situasi dan keadaan seperti ini tidak bisa dibiarkan karena ini bisa dikategorikan sebagai pelanggaran hak asasi manusia dalam bidang pendidikan. Untuk mengakomodir masalah dan persoalan ini negara telah membuat suatu kebijakan peraturan pendidikan yang tertuang dalam Undang-undang Nomor 20 tahun 2003 Tentang Sistem pendidikan nasional dan Peraturan Menteri Pendidikan Nasional Nomor 70 Tahun 2009 Tentang pendidikan inklusif bagi peserta didik yang memiliki kelainan dan memiliki potensi kecerdasan dan/atau bakat istimewa serta Konvensi Hak Anak yang telah ditandatangai hampir semua negara.

Kondisi di atas perlu dipahami dan ditanggapi oleh pengelola sekolah, guru, agar pelayanan pendidikan dapat dilaksanakan sesuai dengan kebutuhan dan keunikan setiap peserta didik terutama peserta didik yang berkebutuhan khusus. Karena mengajar anak dengan beragam latar belakang merupakan sebuah tantangan yang menarik, dibutuhkan pemahaman yang cukup mendalam agar dapat memberikan pelayanan pendidikan yang baik dan optimal serta efektif kepada semua anak didik. Karena sesungguhnya tidak ada manusia lahir dengan pengetahuan yang utuh, tetapi ia dilahirkan dengan naluri belajar. Namun, seringkali naluri belajar anak, dengan keingintahuannya yang besar terbunuh secara perlahan-lahan oleh sistem pendidikan dan ketidaknyaman lingkungkan belajar yang ada. Kondisi anak-anak yang memiliki kebutuhan khusus seperti itu perlu ada sekolah khusus yang bisa mewadahi dan memberikan solusi terhadap kesulitan ataupun kekurangan yang mereka miliki yakni sekolah inklusi.

Penerimaan dan penempatan peserta didik dengan berkebutuhan khusus ke dalam sekolah dasar umum tidak bisa serta merta dikatakan sebagai sekolah inklusi. Namun sesungguhnya sekolah inklusi yang berkualitas lebih dari tindakan fisik seperti itu. Perlu adanya perencanaan yang matang bagi kehadiran anak berkebutuhan khusus ke dalam sekolah inklusi, sehingga anak berkbutuhan khusus dapat mengembangkan dirinya secara optimal, sejalan dengan tujuan pendidikan nasional yang termaktub dalam Undang-undang No 20 Tahun 2003 tentang Sistem pendidikan Nasional yakni mengembangkan manusia Indonesia dan mencerdaskan kehidupan bangsa. Manusia yang mempunyai takwa dan iman kepada Tuhan Yang Maha Esa dan mempunyai budi pekerti yang luhur, mandiri, kepribadian yang mantap, kesehatan rohani, dan jasmani, ketrampilan dan pengetahuan, dan terakhir mempunyai rasa tanggung jawab untuk berbangsa dan bermasyarakat. Dengan demikian dalam pendidikan ada proses memberdayakan manusia menjadi manusia yang seutuhnya agar dapat mengaktualisasikan diri, memahami diri serta dapat menghidupi dirinya sendiri.

Pendidikan inklusif pada hakekatnya adalah bagaimana memahami segala kesulitan pendidikan yang dihadapi oleh peserta didik. Anak berkebutuhan khusus misalnya, mereka mendapat kesulitan untuk mengikuti kurikulum yang ada, tidak mampu mengakses cara membaca menulis secara normal, atau kesulitan mengakses lokasi sekolah, penyesuain dengan lingkungan yang baru. Pendekatan pendidikan inklusi dalam hal ini tidak seharusnya melihat hambatan ini dari sisi peserta didik yang memiliki kelainan, melainkan melihat hambatan ini dari sistem pendidikannya sendiri, kurikulum yang belum sesuai untuk mereka, sarana dan aksesibilitas yang tersedia belum memadai, belum ada guru yang siap melayani mereka, penerimaan peserta didik non disabilitas terhadap kehadiran anak berkebutuhan khusus yang belum maksimal. Dengan 
demikian untuk merubah yang tereksklusikan menjadi terinklusi adalah dengan mengidentifikasi hambatan atau kesulitan yang dihadapi peserta didik dan mengupayakan sekolah umum/inklusi agar dapat meningkatkan kemampuannya dalam mengatasi hambatan-hambatan tersebut sehingga dapat dipenuhi kebutuhan pendidikan anak berkebutuhan khusus.

Sekolah inklusi tidak hanya ditentukan oleh penempatan dan penerimaan siswa oleh sekolah umum terhadap anak berkebutuhan khusus, tetapi didasarkan pada penciptaan lingkungan yang mendukung, aman, nyaman, (Retha Retha Meier, Nikki L. Murdick, Cara Lytle: 2014) dan mencakup semua yang dipelajari. Adanya perencanaan, dukungan, tersedianya sumber daya yang diperlukan untuk peningkatan pembelajaran siswa, baik sumberdaya manusia maupun sumberdaya non manusia seperti sarana prsarana. Sayangnya, terkadang siswa berkebutuhan khusus terpapar pada situasi dan manajemen peserta didik yang kurang memadai sehingga semakin menghambat perkembangan dan pemberdayaan kemampuan mereka, terkadang mereka harus berhadapan dengan guru yang tidak terlatih, lingkungan yang kurang kondusif untuk belajar, sarana prasarana yang minim.

Prinsip penerapan kelas inklusi adalah membuat semua siswa merasa disambut, ditantang dengan tepat, dan didukung dalam upaya mereka mengembangkan diri, minat dan bakat mereka. Lingkungan inklusif, ramah pembelajaran (LIRP) menyambut, memelihara, dan mendidik semua anak tanpa memandang semua perbedaan yang ada. "Inklusif" di lingkungan sekolah umumnya merujuk pada inklusi bagi anak-anak berkebutuhan khusus. Dalam dekade terakhir, banyak sekolah-sekolah reguler telah mengambil bagian menjadi sekolah lingkungan dan proses pembelajaran ramah anak dengan fokus pada hak-hak anak untuk belajar. Menjadi ramah pembelajaran adalah penting, tetapi tidak cukup. Dibutuhkan keterlibatan semua pihak dalam proses ini, artinya semua pelaku pendidikan yang ada di sekolah terutama Guru dan siswa berproses bersama.

\section{METODE PENELITIAN}

Artikel ini disusun dengan metode deskriptif kualitatif melaui kajian literatur, observasi dan wawancara di lapangan. Mengkaji jurnal yang relevan sebagai referensi tentang manajemen peserta didik bagi anak berkebutuhan khsusus dengan pendekatan lingkungan inklusi dan ramah pembelajaran dan hasil studi lapangan berupa observasi dan wawancara dengan Kepala sekolah dan Guru Pembimbing khusus di SDN Kebonsari 2 Malang. Observasi yang dimaksud adalah peneliti melakukan pengamatan langsung bagaimana tahap-tahap atau proses pesserta didik yang mengalami kebutuhan khusus dapat diterima di sekolah reguler sampai dengan keseharian pserta didik di sekolah reguler tersebut. Wawancara yang dilakukan semi terstruktur terkait dengan data yang dibutuhkan untuk menjawab mengenai manajemen peserta didik anak berkebutuhan khusus melalui pendekatan inklusih ramah pembelajaran. Observasi dan wawancara diadakan agar penulis dapat memperoleh informasi sebagai data-data otentik dan bisa dipercaya yang dibutuhkan dalam penulisan artikel ini, sehingga hasil dari temuan ini dapat dijadikan bahan refleksi dan inspirasi bersama dalam memahami manajemen peserta didik bagi anak berkebutuhan khusus dengan pendekatan lingkungan inklusi dan ramah pembelajaran di lingkungan sekolah dasar reguler.

\section{HASIL DAN PEMBAHASAN}

Berdasarkan Surat Keputusan Kepala Dinas Kota Malang yang dikeluarkan setiap awal Tahun Ajaran Baru bahwa setiap sekolah reguler yang telah ditunjuk sebagai sekolah inklusi wajib menerima peserta didik berkebutuhan khusus sambil mempertimbangkan sumberdaya yang dimiliki dan jumlah peserta didik yang akan dilayani dalam satu rombongan belajar maksimal dua 
peserta didik dan tidak memiliki lebih dari dua ketunaan. Dan penerimaan siswa baru berkebutuhan khusus hanya diterima di luar jaring artinya penerimaan tidak secara online dengan maksud supaya segera dilakukan observasi berdasarkan catatan dari tenaga ahli atau tenaga yang berwewenang dalam hal ini psikolog. Catatan ini merupakan hasil asesmen awal terkait dengan kondisi fisik, kemampuan akademik, fungsional, sosial, sensorik dan motorik. Berdasarkan catatan awal tadi, pihak sekolah segera melakukan observasi yang dilakukan oleh Guru Pembimbing Khusus (GPK), seperti yang dilakukan oleh Sekolah Dasar Negeri Dua Kebonsari Malang, waktu observasi dilakukan sebanyak tiga kali dengan durasi waktu observasi selama satu sampai dengan satu setengah jam. Interval waktu dari obseravsi awal ke observasi selajutnya satu sampai dua minggu. Setelah melewati tahap observasi, dan apabila dari catatan observasi guru pembimbing khusus bahwa anak tersebut bisa dimasukkan ke sekolah reguler maka diterima dan apabila sebaliknya karena kondisi atau kemampuan anak berkebutuhan khusus tersebut terlampau berat maka akan diarahkan ke sekolah luar biasa (SLB).

Dalam tahap observasi, langkah yang diambil oleh guru pendamping khusus selain mempelajari catatan dari psikolog juga menggali informasi dan komunikasi langsung dengan orang tua atau wali dari anak berkebutuhan khusus terkait dengan kebiasaan-kebiasaan anak dan juga lingkungan awal si anak berkebutuhan khusus itu hidup bertumbuh dan berkembang, yang tidak tercatat dalam asesmen awal, seperti terungkap dalam satu kasus yang sudah ditangani oleh guru pendamping khusus di sekolah reguler, di mana pada saat datang anak tersebut tidak bisa berbicara dan didiagnosa tunarungu wicara, namun guru pendamping khusus ini karena sudah berpengalaman dan berkualifikasi guru lulusan pendidikan luar biasa tidak percaya begitu saja dengan catatan awal namun kembali melakukan penyelidikan mendalam melalui keluarga atau wali anak berkebutuhan khusus. Dan dari hasil penyelidikan tersebut ternyata anak yang berkebutuhan khusus ini tidak mengalami tunarungu wicara tetapi karena keadaan di mana orang tua kandung dari anak berkebutuhan khusus ini juga mengalami kebutuhan khusus (kedua-duanya tunarungu) sehingga anak ini tidak pernah diajarkan atau diajak berkomunikasi dengan bahasa verbal yang jelas seperti anak normal pada umumnya. Dan hasilnya sekarang anak ini sudah bisa berbicara normal namun ada konsonan-konsonan tertentu tidak jelas pelafalannya.

Langkah selanjutnya setelah melewati masa obrsevasi yang telah ditentukan dan dinyatakan diterima maka langkah berikutnya anak berkebutuhan bersama dengan peserta didik lain yang non berkebutuhan khusus melakukan orientasi sekolah, pada pada saat ini pihak sekolah yang digerakkan oleh guru pembimbing khusus memperkenalkan lingkungan dan teman baru anak berkebutuhan khusus dengan anak non berkebutuhan khusus dan di sinilah terjadi interaksi sosial pertama antara anak berkebutuhan khusus dan anak non berkebutuhan khusus. Praktek seperti ini dinilai oleh Guru pembimbing khusus cukup berhasil dan hal ini terlihat dalam perjalanan proses pembelajaran bagaimana anak-anak berkebutuhan khusus dan non berkebutuhan khusus saling membantu dan saling melengkapi kekurangan masing-masing sehingga ada terjadi proses belajar bersama-sama.

Proses penerapan lingkungan inklusi ramah pembelajaran yang dilakukan di sekolah reguler ini terkait dengan kelas inklusi, di sekolah ini terdiri dari dua kelas yakni kelas inklusi dan kelas reguler. Peserta kelas iknklusi terdiri dari 11 peserta dengan jenis ketunaan autis dan tunagrahita ringan. Sekolah ini belum bisa menerima jenis ketunaan tunarungu karena belum memiliki tenaga terapis bicara. Kegiatan belajar mengajar di lakukan di kelas masing-masing, hanya pada pelajaran tertentu dilakukan bersama-sama. Di kelas inklusi ini ditangani oleh dua orang guru pembimbing khusus sebagai satu team kerja. Dengan tugas selain mengajar, kedua guru pembimbig khusus ini menyusun dan memodifikasi kurikulum sesuai dengan kemampuan 
perserta didik yang menjadi layanan mereka. Dalam team kerja ini tidak hanya dua guru pembimbing khusus dan guru reguler yang ada, tetapi juga bekerja sama dengan tim pembuat soal dari Dinas Pendidikan Kota Malang khusus untuk soal-soal penilaian akhir tahun dan Ujian Sekolah.

Satu konsep penting yang harus disadari adalah bahwa "Semua Anak Berbeda," namun memiliki hak yang sama untuk pendidikan, (Smith, J. D.:2018, hlm 58) tidak peduli apa latar belakang atau kemampuan mereka. Banyak sekolah dan sistem pendidikan bergerak menuju "pendidikan inklusif" di mana anak-anak dengan latar belakang dan kemampuan yang beragam dicari dan didorong untuk mengikuti proses pembelajaran di sekolah biasa. Dengan menghadirkan anak berkebutuhan khusus di sekolah reguler berarti memberi kesempatan mereka untuk belajar dan berinteraksi dengan anak-anak lain tanpa ada sekat perbedaan, dan masing-masing peserta didik dapat belajar menghargai perbedaan.

Dengan interaksi sosialisasi peserta didik belajar bersosialisasi sebagaiman yang disampaikan Niktin bahwa sosialisasi adalah proses dan hasil dari dimasukkannya seorang individu dalam hubungan sosial (Nikitin, 1998). Dalam sosialisai ini terjadi proses interaksi multi arah. Sosialisasi yang baik terjadi jika ada proses integrasi individu dalam sistem sosial (T. Parsons, R. Merton), dan sebagai proses aktualisasi diri dari identitas diri, aktualisasi diri, dari potensi dan kemampuan seseorang sebagai proses mengatasi pengaruh lingkungan yang menghambat pengembangan diri dan penegasan diri dari kepribadian konkret (A. Maslow, C. Rogers). Ilmuwan Rusia (Kon, 2010; Mudrik, 2004) menunjukkan dualitas sosialisasi. Ini berarti bahwa anak belajar pengalaman sosial baru dan, pada saat yang sama, mereproduksi hubungan sosial tertentu yang mempengaruhi lingkungan. Lebih lanjut dalam teori sosial-budaya Vygotsky menggambarkan pembelajaran sebagai proses sosial dan asal mula kecerdasan manusia dalam masyarakat atau budaya, karena itu pentingnya membangun interaksi sosial yang hangat, ramah, dan bersahabat di awal memasuki lingkungan baru bagi anak berkebutuhan khusus karena ini sebagai dasar dalam mengembangkan kognisi anak. Vygotsky berpendapat bahwa ada dua level yang dipelajari dalam proses pembelajaran yakni pertama, melalui interaksi kita dengan orang lain kemudian mengintegrasikan apa yang telah dipelajari ke dalam struktur mental individu. Kedua, potensi perkembangan kognitif terbatas pada zona perkembangan proksimal yakni area eksplorasi di mana peserta didik dipersiapkan secara kognitif, tetapi membutuhkan bantuan dan interaksi sosial untuk dikembangkan (Phidea H. Mapunda1, dkk:2017)

Penerapan manajemen peserta didik Anak berkebutuhan khusus dengan pendekatan lingkungan ingklusi ramah pembelajaran dimaksudkan adalah bagaimana sekolah tersebut memberdayakan semua pelaku pendidikan yang ada agar dapat berproses bersama dalam lingkungan yang ramah termasuk keamanan dan kenyamannan dalam proses belajar mengajar (Retha Retha Meier, Nikki L. Murdick, Cara Lytle: 2014), dan bagaimana membangun kerja sama sebagai satu komunitas pendidikan yang saling memberdayakan seperti adanya tim kerja guru. Maksud dan manfaat dari adanya tim kerja guru adalah sebuah strategi edukatif (Marzia Mazzer; 2015) yang menunjang dan mendorong terjadinya lingkungan yang inklusi dan ramah pembelajaran untuk memfasilitasi partisipasi aktif semua siswa khususnya anak berkebutuhan khusus (Andrich, S. and Miato, L:2003). Maksud bekerja sama dalam tim adalah 1) Berbagi pengetahuan: sebagai satu tim kerja dalam sekolah reguler para guru diharapkan dapat saling membagi pengalaman dan pengetahuan tentang bagaimana mengajar dan mendampingi anak berkebutuhan khusus sesuai dengan kualifikasi di bidang masing-masing namun saling melengkapi. 2) Merencanakan bersama mengenai proses dan strategi belajar mengajar agar efektif bagi perserta didik yang berkebutuhan khusus, 3) Team teaching di kelas; sebagai team teaching 
kedua guru berbagi tanggungjawab untuk menyampaikan instruksi, penilaian dan manajemen kelas dan untuk memberikan dukungan dan akomodasi untuk memenuhi kebutuhan semua siswa (Cook, L:2004) serta mendukung strategi belajar mengajar yang lebih partisipatif untuk meningkatkan rasa memiliki dalam kelompok dan menumbuhkan emapti dan perilaku prososial serta meningkatkan daya saing akademik yang sehat di antara peserta didik.

Dalam pelaksanaan manajemen peserta didik bagi anak berkebutuhan khusus juga dibutuhkan dukungan melalui layanan dukungan lainnya seperti pusat penasihat sekolah misalnya dinas pendidikan setempat dan kerja sama antar sekolah penyelenggara sekolah inklusi dan tenagatenaga ahli yang bisa memberikan bantuan yang efektif dan optimal bagi anak berkebutuhan khusus. Dengan menjalin kerja sama seperti ini mau menunjukkan bahwa kekuatan kreatif, pengetahuan dan keahlian, serta fasilitas sekelompok sekolah, melebihi kekuatan sekolah asal dalam mengatasi masalah-masalah yang dihadapi oleh sekolah terutama oleh guru pembimbing khusus dalam membantu dan membimbing anak berkebutuhan khusus.

\section{KESIMPULAN}

Berdasarkan uraian dalam pembahasan dan hasil studi lapangan disimpulkan bahwa manajemen peserta didik anak berkebutuhan khusus dengan pendekatan lingkungan inklusi ramah pembelajaran adalah sebuah proses dalam memberdayakan sumber daya manusia yang ada di sekolah sebagai subyek pendidikan, dimana semua pelaku pendidikan ini saling memberdayakan diri melalui proses interaksi sosial, dengan tujuan mengasah kepekaan akfektif dan kecerdasan secara kognitif. Dengan demikian sekolah dasar reguler yang terinklusi adalah sarana untuk menciptakan lingkungan perkembangan seluruh aspek kehidupan peserta didik yang berkebutuhan khusus dan pelaku pendidikan lainnya dengan lebih optimal. Melalui manajemen peserta didik yang baik, maka tercipta kondisi yang memungkinkan dan terpenuhi kebutuhan kekhususan anak berkebutuhan khusus agar dapat lebih berpartisipasi dalam mengembangkan dirinya. Seperti tersedianya guru pembimbing khusus yang berkualifikasi di bidangnya, tenaga tarapis sesuai dengan kondisi ketunaan yang ada di dalam sekolah tersebut.

Setelah melihat keadaan di lapangan, satu hal yang bisa penulis sampaikan sebagai rekomendasi bahwa dalam menyelenggarakan pendidikan inklusi yang ramah pembelajaran perlu keterlibatan berbagai pihak dan bagi penyelenggara pendidikan supaya menyediakan layanan pendidikan yang memadai seperti tersedianya sumberdaya manusia yang berkualifikasi seperti tenaga pendidik pembimbing khusus diharapkan berkualifikasi dari pendidikan luar biasa, terapis yang sesuai dengan masing-masing ketunaan, sehingga ketika berjumpa dengan anak-anak berkebutuhan khusus dapat langsung ditangani.

\section{DAFTAR PUSTAKA}

Andrich, S. and Miato, L. 2003, La didattica inclusiva. Organizzare apprendimento cooperativo. Erickson, Trento.

Cook, L. 2004, Co-Teaching: Principle, Practice, and Pragmatics. Northridge, California.

Cottini, L. 2011, L'autismo a scuola. Quattro parole chiave per l'integrazione, Carocci, Roma.

C.J.W. Meijer. 2001, Inclusive Education and Effective Classroom Practices, European Agency for Development in Special Needs Education, ISBN: 87-90591-15-1

Elena V. Zvoleyko, Svetlana A. Kalashnikova, Tatiana K. Klimenko. 2016,

Socialization of students with disabilities in an inclusive educational environment, International Journal Of Environmental \& Science Education,Vol. 11, No. 14, 6469-6481 
Embracing Diversity: Toolkit for Creating Inclusive Learning-Friendly Environments, UNESCO Bangkok

KonI.S.: 2010, Socialization of Children in a Changing World.Questions of education, , No. 1 (2), $18-24$.

Mazzer M. 2015, Inclusion of Students with Autism Spectrum Disorders in Italian Schools: From Theory to Practice, Department of Movement, Human and Health Sciences, University of Rome "Foro Italico", Rome, Italy

MudrikA.V. 2004, Socialization of the person. Moscow: Academy,.

Mapunda, P.H., Abich D. Omollo, and Theodora A. L. Bali, 2017, Challenges in identifying and serving students with special needs in Dodoma, Tanzania, Journal Internasional of Child Care and Education Policy, Mapunda et al. ICEP (2017) 11:10 DOI 10.1186/s40723-0170036-8

Nikitin V.A. : 1998, Beginnings of Social Pedagogy. Moscow Psychological and Social Institute: Flint,

Smith, J. D. 2018. Sekolah untuk Semua: Teori dan Implementasi Inklusi. Bandung: Nuansa Cendekia, Cetak II edisi Revisi, hlm 58)

TarabaevaV.B. 2014. Inclusive education as the factor of socialization of children with disabilities in schools of the Belgorod region. Scientific results., No.2, 114-120. 